\title{
Steroid-induced ocular hypertension in Asian children with severe vernal keratoconjunctivitis
}

This article was published in the following Dove Press journal:

Clinical Ophthalmology

2 August 2012

Number of times this article has been viewed

\author{
Marcus Ang' \\ Seng-Ei Ti' \\ Raymond Loh' \\ Sonal Farzavandi' \\ Rongli Zhang² \\ Donald Tan' \\ Cordelia Chan'
}

'Singapore National Eye Centre, Singapore; ${ }^{2}$ Singapore Eye Research Institute, Singapore
Correspondence: Cordelia Chan

Singapore National Eye Centre, II Third Hospital Avenue, Singapore 168751

Tel +65 62277255

Fax +65 62277290

Email cordelia.chan.m.l@snec.com.sg
Background: We describe clinical characteristics and risk factors for corticosteroid response in children with severe vernal keratoconjunctivitis (VKC).

Design: Retrospective, noncontrolled, comparative case series.

Participants: Patients from three tertiary centers in Singapore.

Methods: We reviewed patients with severe VKC (clinical grade > 2) who were on topical steroid therapy, with a minimum follow-up period of 1 year post-presentation. Logistic regression was used to determine risk factors for corticosteroid response.

Main outcome measure: Corticosteroid response was defined as intraocular pressure (IOP) $>21 \mathrm{mmHg}$ (three consecutive readings), or a rise of more than $16 \mathrm{mmHg}$ from baseline, after commencement of steroid therapy in the absence of other possible causes of raised IOP. Results: Forty-one of 145 (28.3\%) patients developed a corticosteroid response, of which eight (5.5\%) progressed to glaucoma. The overall mean age of onset of VKC was $9.9 \pm 4.4$ years. Longer duration of corticosteroid use (OR, 5.06; 95\% CI: 1.04-25.56; $P=0.45)$ and topical dexamethasone $0.01 \%(\mathrm{OR}, 2.25$; 95\% CI: 1.99-5.08; $P=0.40)$ were associated with corticosteroid response. Mixed type of VKC (OR, 9.76; 95\% CI: 3.55-26.77; $P<0.001$ ), the presence of limbal neovascularization of $\geq$ three quadrants (OR, 6.33; 95\% CI: $2.36-16.97 ; P<0.001$ ), and corneal involvement (OR, 3.51; 95\% CI: 1.31-9.41; $P=0.012)$ were significant clinical risk factors after adjusting for potential confounders such as age, sex, ethnicity, duration, and type of corticosteroid used.

Conclusion: Children on long-term oral corticosteroids with severe, mixed-type VKC and corneal involvement are more likely to develop corticosteroid response, and may require early treatment to prevent progression to glaucoma.

Keywords: vernal keratoconjunctivitis, glaucoma, steroids

\section{Introduction}

Vernal keratoconjunctivitis (VKC) is a bilateral chronic inflammation of the conjunctiva that mostly affects children and young adult males. ${ }^{1}$ While the term "vernal" suggests a seasonal pattern of disease, VKC is often persistent in warm, tropical climates around Asia, ${ }^{2,3}$ up to a quarter of seasonal cases evolving into perennial disease 3 years from the onset of disease. ${ }^{4}$ These eyes may be at higher risk of permanent visual impairment due to complications including corneal scarring $(6 \%)$, cataract formation, and corticosteroid-induced glaucoma $(2 \%-7 \%) .{ }^{4-6}$

A chronic disease, up to $85 \%$ of patients with $\mathrm{VKC}$ will require corticosteroids at some point during the course of their illness. ${ }^{7}$ As a result, when treating patients with severe and chronic VKC, clinicians should be vigilant of the corticosteroid response, 
as corticosteroid-induced ocular hypertension (OHT) may progress to glaucoma with permanent visual field loss, even after corticosteroid therapy is discontinued and the intraocular pressure (IOP) has returned to normal. ${ }^{8,9}$ The association between type and duration of corticosteroid therapy and secondary glaucoma has been inconsistent in the literature, as much depends on the individual's response, a complex genetic mechanism proposed as an explanation for this. ${ }^{10}$ In this study we describe the clinical characteristics, incidence, and risk factors for developing corticosteroid-induced OHT and glaucoma in our patients with severe VKC.

\section{Materials and methods}

We conducted a retrospective review of all consecutive patients diagnosed with severe VKC at three major tertiary hospitals in Singapore: Singapore National Eye Center, Changi General Hospital, and Kandang Kerbau Women's and Children's Hospital. All patients first presented from January 1, 2007 to December 31, 2008. The medical records of patients diagnosed with severe VKC (clinical grade $>2$ ) as defined by Bonini et al, ${ }^{11}$ on topical steroid therapy, and with a minimum follow-up period of 1 year post-presentation, were reviewed. Data collected included: (1) patient demographics; (2) duration of disease; (3) history of atopy/systemic associations (asthma, eczema) or significant family history; (4) symptoms (itch, redness, mucoid discharge, glare, and photophobia); (5) signs (detailed slit lamp examination findings of the eyelids, conjunctiva, cornea, and optic nerve head); (6) maximum and mean IOP readings using Goldmann applanation tonometry or Tonopen XL (Reichert Ophthalmic Instruments, Depew, NY), with onset of raised IOP; (7) number of recurrent episodes requiring a visit; (8) investigations such as skin tests, serum eosinophil levels, and histology; (9) treatment instituted (lubricants, mast cell stabilizers, topical or systemic steroids, and antihistamines, including the dosage, frequency, and duration of use); and (10) surgical procedures performed.

The presence of papillae was evaluated based on size (medium papillae $0.3-1 \mathrm{~mm}$, and giant papillae $1-3 \mathrm{~mm}$ ). Type of VKC was classified as palpebral if papillae were predominantly on the upper tarsal conjunctiva, limbal if papillae or gelatinous deposits were at the limbus with minimal papillae on the upper tarsus, and mixed if both were present. ${ }^{11}$ Corneolimbal neovascularization was considered significant if present in more than three quadrants of the limbus in both eyes. Corneal involvement included the presence of a corneal epitheliopathy, corneal or shield ulcers, and plaques. ${ }^{12}$
Corticosteroid response was defined according to published criteria: an increase of IOP to greater than $21 \mathrm{mmHg}$ for more than three consecutive readings or a rise of $16 \mathrm{mmHg}$ from baseline, after commencement of steroid therapy in the absence of other possible causes of raised IOP. ${ }^{13,14}$ Corticosteroid-induced glaucoma was diagnosed in the presence of concurrent glaucomatous optic nerve head changes and/or glaucomatous visual field defects on Humphrey 24-2 full threshold test in patients of appropriate age who could perform the test reliably. ${ }^{10}$ These patients were required to have at least one reliable baseline visual field (false positive, false negative, and fixation loss rates all below 15\%). A glaucomatous field defect was considered if two consecutive reliable visual field tests revealed at least three contiguous points on the pattern deviation plot with sensitivity depressed below $P<5.0 \%$. Patients with previous ocular surgery, trauma, or other possible secondary causes of glaucoma were excluded from the study. We compared patients who developed steroid response to those who were normotensive throughout the study period as controls.

In our practice, patients who were diagnosed with steroid response were monitored closely and started on antiglaucoma medication in a step-wise fashion until an individualized target IOP was achieved. Thereafter, drug therapy was tapered until the IOP was controlled without medication. Patients with glaucomatous optic nerve head changes or glaucomatous visual field defects were referred to a glaucoma subspecialist for further management. In patients whose IOP could not be controlled on maximal anti glaucoma therapy and in whom surgery was indicated, trabeculectomy with adjuvant topical mytomycin-C (0.02\% applied for 3-5 minutes) was performed in the affected eyes.

The statistical software SPSS 17.0 (IBM Corporation, Armonk, NY) was used for statistical analyses. We determined that with a power of $80 \%$ and alpha error of 0.05 , we would require at least 40 cases and 80 controls to detect a difference of $20 \%$ between variables for cases and controls. Statistical analysis included descriptive statistics, where the mean and standard deviation (SD) with 95\% confidence intervals (CI) was calculated for the continuous variables, while frequency distribution and percentages were used for categorical variables. We used the Student's $t$-test (unpaired) and Chi-square test for categorical variables. Trend analyses within variables were assessed using two-way analysis of variance (ANOVA) for both the groups separately. Age- and sex-adjusted, multivariate logistic regression was used to evaluate risk factors associated with steroid response while 
adjusting for possible confounders, and odds ratios (OR) with $95 \%$ CI were also calculated. A $P$-value $<0.05$ was considered statistically significant.

\section{Results \\ Demographics}

A total of 145 patients met our inclusion criteria of which, demographics and clinical characteristics are described in Table 1. The overall mean age of onset of VKC was $9.9 \pm 4.4$ years. Most patients were male $(n=115,79.3 \%)$ and all patients were of Asian descent, mainly of Chinese ethnicity $(\mathrm{n}=101,69.7 \%)$. The mean logMAR baseline best corrected visual acuity was $0.33 \pm 0.29$. All patients had severe (grade $>2$ ) and persistent symptoms throughout the year, with a mean of $3.5 \pm 2.6$ recurrences (requiring a clinic visit). We did not find significant differences in the prevalence of diseases such as asthma, eczema, or previous use of systemic steroids, including nasal spray (Table 1). The most common form of VKC in our Asian study cohort was the palpebral type $(n=89,61.4 \%)$. However, there was a higher proportion of mixed-type VKC compared with tarsal or limbal VKC ( $\mathrm{n}=31,75.6 \%$ versus $\mathrm{n}=20,19.2 \%)$ amongst the steroid responders $(P<0.001)$.

\section{Clinical features of corticosteroid responders}

The clinical characteristics comparing corticosteroid responders and nonresponders are summarized in Table 2. There were more clinical recurrences in the corticosteroid responder group of patients (mean recurrences per year $=1.0 \pm 0.7$,
$P=0.003)$. The mean onset of raised IOP was detected $8.4 \pm 6.8$ weeks after commencing topical corticosteroid therapy. The mean maximum IOP was $26.5 \pm 2.8 \mathrm{mmHg}$ in the corticosteroid responders as opposed to $16.3 \pm 2.9 \mathrm{mmHg}$ in the controls who did not develop corticosteroid response $(P<0.001)$. There was a significant difference in the mean rise in IOP from baseline in the corticosteroid responders as compared to the control group $(19.8 \pm 2.6 \mathrm{mmHg}$ versus $3.9 \pm 3.0 \mathrm{mmHg}, P<0.001)$.

Amongst the corticosteroid responders, the most common antiglaucoma medication used was timolol $0.5 \%$ ( $\mathrm{n}=18,43.9 \%$ ). In patients who could not tolerate timolol (eg, asthmatics), prostaglandin analogs such as latanoprost $(\mathrm{n}=11,26.8 \%)$ and travaprost $(\mathrm{n}=7,17.1 \%)$, as well as brimonidine ( $\mathrm{n}=7,17.1 \%)$ were prescribed with the recognized risk of worsening inflammation or symptoms. Most patients required only one antiglaucoma medication $(\mathrm{n}=28,68.3 \%)$, while 13 patients $(31.7 \%)$ required two different medications for adequate IOP control. Of the eight patients that developed steroid-response glaucoma, six patients $(4.1 \%)$ eventually underwent trabeculectomy with topical mytomycin-C. This has been described in a previous publication. ${ }^{15}$ In these patients, IOP was well controlled in five out of six eyes, with a mean follow up of $17.6 \pm 4.5$ months.

\section{Clinical risk factors for corticosteroid response}

There were $41 / 145$ (28.3\%) corticosteroid responders of which eight (5.5\%) developed glaucomatous nerve damage

Table I Demographics and medical history of study cohort

\begin{tabular}{|c|c|c|c|c|}
\hline Characteristics $^{\dagger}$ & $\begin{array}{l}\text { Total } \\
(n=145)\end{array}$ & $\begin{array}{l}\text { Noncorticosteroid responders } \\
(n=104)\end{array}$ & $\begin{array}{l}\text { Corticosteroid responders } \\
(n=4 I)\end{array}$ & $P$-value* \\
\hline \multicolumn{5}{|l|}{$\operatorname{Sex}(\%)$} \\
\hline Male & II $5(79.3)$ & $83(79.8)$ & $32(78.0)$ & 0.814 \\
\hline Female & $30(20.7)$ & $21(20.2)$ & $9(22.0)$ & \\
\hline Mean age of onset, years (SD) & $9.9(4.4)$ & $10.2(4.9)$ & $9.2(2.9)$ & 0.128 \\
\hline \multicolumn{5}{|l|}{ Ethnicity (\%) } \\
\hline Chinese & 101 (69.7) & $70(67.3)$ & $31(75.6)$ & 0.671 \\
\hline Malay & $26(I 7.9)$ & $21(20.2)$ & $5(12.2)$ & \\
\hline Indian & $13(9.0)$ & $9(8.7)$ & $4(9.8)$ & \\
\hline Others & $5(3.4)$ & $4(3.8)$ & I (2.4) & \\
\hline \multicolumn{5}{|l|}{ Medical history } \\
\hline Asthma (\%) & $57(39.3)$ & $42(40.4)$ & $15(36.6)$ & 0.673 \\
\hline Eczema $(\%)$ & $68(46.9)$ & $43(4 \mid .3)$ & $25(6 \mid .0)$ & 0.033 \\
\hline Allergic rhinitis (\%) & $68(46.9)$ & $49(47.1)$ & $19(46.3)$ & 0.933 \\
\hline Family history of atopy (\%) & $18(12.4)$ & $15(14.4)$ & $3(7.3)$ & 0.243 \\
\hline Previous steroid therapy (\%) & $6(4.1)$ & $2(1.9)$ & $4(9.8)$ & 0.054 \\
\hline
\end{tabular}

Notes: ${ }^{\dagger}$ Data presented are means (standard deviations [SD]) or number (\%), as appropriate; ${ }^{*}$-value for the difference in characteristics by case control group based on independent $t$-test or Chi-square test analysis of variance, as appropriate. 
Table 2 Clinical features and treatment of study cohort

\begin{tabular}{|c|c|c|c|c|}
\hline Characteristics $^{\dagger}$ & $\begin{array}{l}\text { Total } \\
(n=145)\end{array}$ & $\begin{array}{l}\text { Noncorticosteroid responders } \\
(n=104)\end{array}$ & $\begin{array}{l}\text { Corticosteroid responders } \\
(n=4 I)\end{array}$ & $P$-value* \\
\hline \multicolumn{5}{|l|}{ Type of VKC (\%) } \\
\hline Mixed & $51(35.2)$ & $20(19.2)$ & $31(75.6)$ & $<0.001$ \\
\hline Palpebral & $89(6 I .4)$ & $79(76.0)$ & $10(24.4)$ & \\
\hline Limbal & $5(3.4)$ & $5(4.8)$ & I (2.4) & \\
\hline Number of recurrences per year (SD) & $0.819(0.577)$ & $0.732(0.497)$ & $\mathrm{I} .04 \mathrm{I}(0.70 \mathrm{I})$ & 0.003 \\
\hline \multicolumn{5}{|l|}{ Intraocular pressure (IOP) } \\
\hline Baseline IOP (mmHg) & $12.2(2.8)$ & $12.6(2.7)$ & II.I (2.8) & 0.003 \\
\hline Maximum IOP $(\mathrm{mmHg})$ & $19.2(6.6)$ & $16.3(2.9)$ & $26.5(2.8)$ & $<0.001$ \\
\hline Rise in IOP $(\mathrm{mmHg})$ & $7.0(7.1)$ & $3.9(3.0)$ & $19.8(2.6)$ & $<0.001$ \\
\hline \multicolumn{5}{|l|}{ Type of topical steroid therapy } \\
\hline Dexamethasone (\%) & $64(44.1)$ & $34(32.7)$ & $30(73.2)$ & 0.040 \\
\hline Fluromethalone (\%) & $49(33.8)$ & $40(38.5)$ & $9(22.0)$ & 0.058 \\
\hline Prednisolone acetate I\% (\%) & $27(18.6)$ & $18(17.3)$ & $9(22.0)$ & 0.518 \\
\hline Optodexine (\%) & $5(3.4)$ & $4(3.8)$ & I (2.4) & 1.0 \\
\hline Oral prednisolone (\%) & $6(4.1)$ & $2(1.9)$ & $4(9.8)$ & 0.031 \\
\hline Topical cyclosporine (\%) & $82(56.6)$ & $44(42.3)$ & $38(92.7)$ & 1.0 \\
\hline
\end{tabular}

Notes: ${ }^{\dagger}$ Data presented are means (standard deviations [SD]) or number (\%), as appropriate; $* P$-value for the difference in characteristics by case control group based on independent $t$-test or Chi-square test analysis of variance, as appropriate.

Abbreviations: IOP, intraocular pressure; SD, standard deviation; VKC, vernal keratoconjunctivitis.

as defined in our study. In these eight patients, mean duration of steroid therapy before detection of glaucomatous damage as defined in our study was $10.8 \pm 6.9$ weeks. None of the corticosteroid responders had a past history of primary open-angle glaucoma or OHT, and none had a positive family history of glaucoma. We found clinical risk factors for corticosteroid response to include patients with mixed type
VKC (OR, 9.76; 95\% CI: 3.56-26.77; $P<0.001)$, significant limbal neovascularization (OR, 6.33; 95\% CI: 2.63-16.97), and corneal involvement (OR, 3.52; 96\% CI: 1.32-9.42; $P=0.012$ ), following adjustment for potential confounders such as age, sex, ethnicity, history of asthma, eczema, systemic corticosteroid use, recurrences, duration, and type of topical corticosteroid (Table 3).

Table 3 Risk factors for steroid response in Asian patients with severe VKC

\begin{tabular}{|c|c|c|c|c|}
\hline \multirow[t]{2}{*}{ Characteristics } & \multicolumn{4}{|l|}{ OR (95\% Cl) } \\
\hline & Age/sex-adjusted & $P$-value & Multivariate $^{\dagger}$ & $P$-value \\
\hline Age of onset & $0.947(0.883,1.01)$ & 0.126 & $1.020(0.921,1.13)$ & 0.706 \\
\hline Sex (male) & $0.914(0.375,2.23)$ & 0.844 & $0.706(0.226,2.20)$ & 0.549 \\
\hline \multicolumn{5}{|l|}{ Ethnicity } \\
\hline Chinese & $1.92(0.171,21.44)$ & 0.685 & $1.14(0.070,18.71)$ & 0.816 \\
\hline Malay & $1.00(0.776,12.97)$ & & $0.537(0.027,10.84)$ & \\
\hline Indian & $2.01(0.141,28.8 I)$ & & $0.917(0.05,16.93)$ & \\
\hline Type of VKC (mixed) & $12.22(5.11,29.20)$ & $<0.001$ & $9.76(3.55,26.77)$ & $<0.001$ \\
\hline History of asthma & $0.82(0.374,1.80)$ & 0.623 & $1.06(0.345,3.29)$ & 0.912 \\
\hline History of eczema & $2.29(1.072,4.89)$ & 0.032 & $1.45(0.560,3.77)$ & 0.443 \\
\hline Systemic corticosteroid treatment & $5.90(1.14,30.25)$ & 0.033 & $1.28(0.298,5.53)$ & 0.737 \\
\hline Longer duration of corticosteroid use & $5.06(1.04,25.56)$ & 0.045 & $0.91(0.803,1.03)$ & 0.163 \\
\hline Higher recurrences per year & $2.44(1.26,4.69)$ & 0.007 & $2.51(0.876,7.20)$ & 0.087 \\
\hline Limbal neovascularization & II.37 $(4.83,26.75)$ & $<0.001$ & $6.33(2.363,16.97)$ & $<0.001$ \\
\hline Corneal involvement & $7.27(3.175,16.675)$ & $<0.001$ & $3.51(1.31,9.4 I)$ & 0.012 \\
\hline \multicolumn{5}{|l|}{ Type of topical corticosteroid } \\
\hline Dexamethasone $0.01 \%$ (PF) & $2.25(1.99,5.08)$ & 0.040 & $1.22(0.396,3.79)$ & 0.724 \\
\hline Fluromethalone $0.1 \%$ (PF) & $0.492(0.199,1.22)$ & 0.126 & $0.556(0.160,1.93)$ & 0.356 \\
\hline Prednisolone acetate I\% (PF) & $1.33(0.538,3.33)$ & 0.535 & $0.654(0.141,3.02)$ & 0.587 \\
\hline
\end{tabular}

Notes: ${ }^{\dagger}$ Adjusted for age of onset, sex, type of VKC, limbal neovascularization (more than three quadrants), corneal involvement, recurrences per year, duration of corticosteroid use, and type of corticosteroid used.

Abbreviations: $\mathrm{Cl}$, confidence interval; OR, odds ratio; PF, preservative-free; VKC, vernal keratoconjunctivitis. 


\section{Treatment risk factors for corticosteroid response}

Patients with a longer duration of corticosteroid use (OR, 5.06; 95\% CI: $1.04-25.56 ; P=0.045)$ and topical dexamethasone $0.01 \%$ (OR, 2.25 ; 95\% CI: $1.99-5.08 ; P=0.40$ ) were associated with corticosteroid response independent of age or sex (Table 3 ). The commonly prescribed types of topical steroid were dexamethasone $(\mathrm{n}=64,44.1 \%)$, fluoromethalone $(\mathrm{n}=49,33.8 \%)$ and prednisolone acetate $1 \%(\mathrm{n}=27,18.6 \%)$. These topical corticosteroids were typically prescribed at a tapering dose from acute exacerbations: six times a day for 2 weeks, reducing to four and then two times a day every 2 weeks until their clinical condition was quiescent. Only six patients (4.1\%) received systemic steroids in the form of oral prednisolone to treat severe VKC symptoms, which was associated with severe eczema or periorbital itch.

\section{Discussion}

Corticosteroid response can occur in Chinese children without VKC in $6 \%-56 \%$ of cases. ${ }^{16-18}$ In other normotensive populations without $\mathrm{VKC}$, corticosteroid induced OHT was found in $0 \%-23 \%$ of cases, with only $0 \%-9 \%$ going on to develop glaucoma. ${ }^{19,20}$ However, comparing the incidence of corticosteroid-induced glaucoma in our study to these studies of nonvernal populations is problematic, as these various groups include different age groups, a spectrum of ethnicities, and differing follow-up periods. In our study of Asian (predominantly Chinese) children with severe VKC living in Singapore, the incidence of corticosteroid-induced glaucoma was $5.5 \%$, which was comparable to other vernal populations in Italy and India $(2 \%-7 \%) .4,6,7$

Corticosteroid-induced glaucoma is an iatrogenic secondary open-angle glaucoma caused by decreased trabecular outflow. ${ }^{10}$ Changes in trabecular meshwork cells have been identified, including increased deposition of several components of the extracellular matrix and rearrangement of the trabecular meshwork cytoskeleton with crosslinking of actin microfilaments. ${ }^{21}$ Reported risk factors for corticosteroid response include type and potency of the corticosteroid, preexisting primary open-angle glaucoma or OHT, and a family history of primary open-angle glaucoma. ${ }^{19,22-24} \mathrm{In}$ our study, we found that patients with clinical signs such as limbal neovascularization and corneal involvement were six and four times more likely to be associated with corticosteroid-induced OHT respectively. These were independent associations even after adjusting for known risk factors such as type and duration of corticosteroid therapy, which could potentially confound our results.
Our study also showed that patients with a mixed form of VKC were associated with an approximately 10 -fold risk of developing corticosteroid response. A previous study also reported that mixed forms of VKC were associated with steroid-induced glaucoma. ${ }^{7}$ It is also recognized that mixed forms of VKC have poorer long-term visual prognosis compared to the tarsal forms as a result of sight threatening complications. ${ }^{6}$ Our study findings suggest that, while type and duration of steroid use contribute to corticosteroid response, there may be corneal inflammatory mechanisms that play a role. Patients with severe VKC on long-term corticosteroid therapy with clinical signs of chronic inflammation should have more aggressive IOP monitoring and control.

We recognize the limitations of our study, which include the small sample size, retrospective nature, and lack of an ideal control group with which to compare the steroid responders. Moreover, it is difficult to analyze the dosage and duration of corticosteroid therapy as a result of patients' variable clinical course, response, and compliance. However, we did adjust for known confounders for corticosteroid response in Asian patients with severe VKC. The results from our clinical study may inspire future studies of cytokines and biomarkers (like vascular endothelial growth factor and matrix metalloproteinase [MMP]) in the ocular surface of patients with VKC, and analysis of their role in the pathophysiology of corticosteroid response in these patients.

\section{Conclusion}

Asian patients who suffer from severe VKC have a perennial and chronic form that often requires long-term corticosteroid therapy, especially for patients with the severe form of the disease. The incidence of corticosteroid response in patients with severe VKC on long-term steroids is greater than expected, and a high index of suspicion is always required. In these young patients, prompt and appropriate IOP control is crucial in preventing rapid deterioration that may culminate in the development of glaucoma. Patients with clinical signs of chronic inflammation must be closely monitored, as they are associated with an increased likelihood of corticosteroid response, independent of duration or type of corticosteroid therapy.

\section{Disclosure}

The authors report no conflicts of interest or financial disclosures in this work.

\section{References}

1. Buckley RJ. Allergic eye disease - a clinical challenge. Clin Exp Allergy. 1998;28(Suppl 6):39-43. 
2. Choi H, Lee SB. Nonseasonal allergic conjunctivitis in the tropics: experience in a tertiary care institution. Ocul Immunol Inflamm. 2008;16(4):141-145.

3. Kosrirukvongs P, Vichyanond P, Wongsawad W. Vernal keratoconjunctivitis in Thailand. Asian Pac J Allergy Immunol. 2003;21(1):25-30.

4. Leonardi A, Busca F, Motterle L, et al. Case series of 406 vernal keratoconjunctivitis patients: a demographic and epidemiological study. Acta Ophthalmol Scand. 2006;84(3):406-410.

5. Tabbara KF. Ocular complications of vernal keratoconjunctivitis. Can J Ophthalmol. 1999;34(2):88-92.

6. Bonini S, Bonini S, Lambiase A, et al. Vernal keratoconjunctivitis revisited: a case series of 195 patients with long-term followup. Ophthalmology. 2000;107(6):1157-1163.

7. Mithal S, Sood AK, Maini AK. Management of vernal conjunctivitis with steroid induced glaucoma - a comparative study. Indian $J$ Ophthalmol. 1987;35(5-6):298-301.

8. Sihota R, Konkal VL, Dada T, Agarwal HC, Singh R. Prospective, long-term evaluation of steroid-induced glaucoma. Eye (Lond). 2008;22(1):26-30.

9. Bielory L. Ocular allergy guidelines: a practical treatment algorithm. Drugs. 2002;62(11):1611-1634.

10. Clark AF. Basic sciences in clinical glaucoma: steroids, ocular hypertension, and glaucoma. J Glaucoma. 1995;4(5):354-369.

11. Bonini S, Sacchetti M, Mantelli F, Lambiase A. Clinical grading of vernal keratoconjunctivitis. Curr Opin Allergy Clin Immunol. 2007; $7(5): 436-441$.

12. Leonardi A, Secchi AG. Vernal keratoconjunctivitis. Int Ophthalmol Clin. 2003;43(1):41-58.

13. Armaly MF. Statistical attributes of the steroid hypertensive response in the clinically normal eye. I. The demonstration of three levels of response. Invest Ophthalmol. 1965;4:187-197.
14. Bartlett JD, Woolley TW, Adams CM. Identification of high intraocular pressure responders to topical ophthalmic corticosteroids. J Ocul Pharmacol. 1993;9(1):35-45.

15. Ang M, Ho CL, Tan D, Chan C. Severe vernal keratoconjunctivitis requiring trabeculectomy with mitomycin $\mathrm{C}$ for corticosteroid-induced glaucoma. Clin Experiment Ophthalmol. 2012;40(4):e149-e155.

16. Fan DS, Ng JS, Lam DS. A prospective study on ocular hypertensive and antiinflammatory response to different dosages of fluorometholone in children. Ophthalmology. 2001;108(11):1973-1977.

17. Ng JS, Fan DS, Young AL, et al. Ocular hypertensive response to topical dexamethasone in children: a dose-dependent phenomenon. Ophthalmology. 2000;107(11):2097-2100.

18. Kwok AK, Lam DS, Ng JS, Fan DS, Chew SJ, Tso MO. Ocular-hypertensive response to topical steroids in children. Ophthalmology. 1997;104(12):2112-2116.

19. Kitazawa Y, Horie T. The prognosis of corticosteroid-responsive individuals. Arch Ophthalmol. 1981;99(5):819-823.

20. Ohji M, Kinoshita S, Ohmi E, Kuwayama Y. Marked intraocular pressure response to instillation of corticosteroids in children. $\mathrm{Am} \mathrm{J}$ Ophthalmol. 1991;15:112(4):450-454.

21. Fingert JH, Clark AF, Craig JE, et al. Evaluation of the myocilin (MYOC) glaucoma gene in monkey and human steroid-induced ocular hypertension. Invest Ophthalmol Vis Sci. 2001;42(1):145-152.

22. Bielory L. Ocular allergy overview. Immunol Allergy Clin North Am. 2008;28(1):1-23, v.

23. Armaly MF. Effect of corticosteroids on intraocular pressure and fluid dynamics. II. The effect of dexamethasone in the glaucomatous eye. Arch Ophthalmol. 1963;70:492-499.

24. Biedner BZ, David R, Grudsky A, Sachs U. Intraocular pressure response to corticosteroids in children. Br J Ophthalmol. 1980;64(6): $430-431$.
Clinical Ophthalmology

\section{Publish your work in this journal}

Clinical Ophthalmology is an international, peer-reviewed journal covering all subspecialties within ophthalmology. Key topics include: Optometry; Visual science; Pharmacology and drug therapy in eye diseases; Basic Sciences; Primary and Secondary eye care; Patient Safety and Quality of Care Improvements. This journal is indexed on

\section{Dovepress}

PubMed Central and CAS, and is the official journal of The Society of Clinical Ophthalmology (SCO). The manuscript management system is completely online and includes a very quick and fair peer-review system, which is all easy to use. Visit http://www.dovepress.com/ testimonials.php to read real quotes from published authors. 